\title{
Teachers' Choices of Teaching Methods for Environmental Education: A case study of Life Skills teachers at a primary school in South Africa
}

\author{
Melishnee Ruthanam, Durban University of Technology; Poovendhree Reddy, Durban University of \\ Technology; Daisy Pillay, University of KwaZulu-Natal, South Africa
}

\begin{abstract}
The success of environmental education has been attributed to several factors including teachers' competencies and attitudes, teaching methodologies, availability of resources, and curriculum design. Many researchers in environmental education suggest that innovative and resourceful teaching approaches may translate into meaningful environmental education. This study provides an insight into the influence of this on environmental education in a South African classroom through a qualitative approach. Interviews were conducted to understand the teaching approaches used in the subject of Life Skills. The findings of the study suggest that the pedagogical content knowledge and identity of the teacher are determining factors for teachers' pedagogical choices. This paper suggests that it is not the resources that are crucial to learning, rather the presence of a resourceful teacher. A resourceful teacher is able to introduce innovation regardless of the availability of teaching resources. This information could inform pre-service teacher training programmes in focusing on the development of a resourceful environmental education teacher.
\end{abstract}

Keywords: environmental education, Life Skills, teaching approaches, Pedagogical Content Knowledge (PCK), educational resources

\section{Introduction}

Environmental education (EE) can be defined as "a process that allows individuals to explore environmental issues, engage in problem solving, and take action to improve the environment. As a result, individuals develop a deeper understanding of environmental issues and have the skills to make informed and responsible decisions" (United States Environmental Protection Agency, 2017). Key outcomes of environmental education are awareness and sensitivity, knowledge and understanding, attitudes, skills and participation. In the South African school environment, the advocate for and facilitator of these outcomes would be the teacher. The role of teachers in environmental education is thus critical (Ramadhan, Sukma \& Indriyani, 2019). It is up to the teacher to adequately educate students in EE through the integration of the outcomes listed above. 
The inclusion of EE in the South African school curriculum creates opportunities for learners to interrogate their own values, beliefs and actions, particularly with respect to sustainable development, social and environmental issues (Shallcross, et al., 2006). While there are no standardised methods for teaching EE, proponents of EE have emphasised holistic and interdisciplinary teaching and learning (Richardson, Liang \& Wake, 2014; Mwendwa, 2017). Environmental education can be considered as education about, in and for the environment (Fien, 1992). Learners can be engaged in learning through critical inquiries into real issues of the environment (Mwendwa, 2017). The implementation of learning strategies such as these in the South African classroom, however, presents numerous challenges which include resource limitations (Winther, Sadler \& Saunders, 2010). However, EE is not solely dependent on resources and infrastructure but includes the teacher as a central component in effective delivery. In this regard, the knowledge base of teachers is important, but their identities are equally important (Kimaryo, 2011; Mwendwa, 2017). A knowledge base is only as good as the teacher's ability to represent and communicate the knowledge and skills to learners (Mwendwa, 2017). In addition, teachers' learned behaviour, personal attitudes and experiences may impact on teaching and learning in EE (Jannah, et al., 2013). The research question that guided this study was: What factors influence pedagogical choices in Environmental Education?

\section{Environmental education in South Africa}

In South Africa, directives to include environmental issues in formal education were mandated decades ago through the White Paper on Education and Training (1995). However, the current policy on Minimum Requirements for Teacher Education does not make explicit reference to environmental education (Reddy, 2017). Since 1995, several curriculum changes have been implemented at the basic education level. For example, Biology was replaced by Life Sciences and the theoretical aspect of environmental education was included in this subject at secondary school (Grade 8-12) level (Department of Basic Education, 2011). Practical aspects of EE are also carried through in the subject of Life Skills at the primary level (Grade R-7). Teachers are meant to link environmental concepts to implementation in everyday life using the platform of Life Skills (Department of Basic Education, 2011; Blyth \& Meiring, 2018). Previous studies have shown that integration of EE into the curriculum is challenging (Loubser, et al., 2014; Mudaly \& Ismail, 2016; Reddy, 2017). Reddy (2017, p. 117) asserted that "the means by which educators achieve the goal of teaching learners about the environment and environmental issues are as important as the curriculum provision themselves".

This implies that Life Skills teachers need to identify and integrate relevant contextual concerns with meaningful learning activities related to EE so that learners develop an understanding of the interrelatedness of the environment, health and well-being (Blyth \& Meiring, 2018). Teachers have been reported to struggle with this requirement, particularly in a resource-strained South African school context. Integrating EE with Life Skills is difficult 
as teachers need to recognise how to realise the particular knowledge and values embodied in this subject, in the form of learner growth and development (Marques \& Xavier, 2020).

Researchers suggest that South African teacher education programmes prepare teachers for content teaching and are primarily focussed on the 'what', instead of the 'how' (Ramsaroop \& Van Rooyen, 2013). Teaching innovation and resourcefulness linked with the 'how' have to include factors such as school contexts, quality and availability of resources and teacher training and experience (Karkkainen, 2012). Resources such as textbooks, internet access, interactive boards and television are unevenly distributed in the South African schooling system and in many schools, these resources are very limited. According to the Department of Basic Education's 2018 statistics, of 23471 public schools, 20071 have no laboratory, 18019 have no library, and 16897 have no internet. However, the mere presence of these resources is not necessarily enough to guarantee that effective teaching and learning will occur (Spaull, 2013). The teacher is an essential component. An imaginative, innovative and resourceful teacher is the key to successful learning (Asiegbu \& Okpala, 2019; Borodina, Sibgatullina \& Gizatullina, 2019). Teachers are an important resource in $\mathrm{EE}$, as their attitude, behaviour and motivation may influence what learners do, think and internalise (Jannah, et al., 2013). 'Individual commitment' has been highlighted as the root for inquiry-based teaching, for example (Cheng \& So, 2015). Teachers with good tacit knowledge of environmental education use this knowledge as a base to inform their initiatives and to integrate supplementary teaching methods to their lessons (Kimaryo, 2011).

\section{Theoretical framing}

Palmer's (2007) theory of identity formed the grounding theory of this study. The theory used to analyse the findings was Shulman's (1987) Theory of Pedagogical Content Knowledge (PCK). Both theories were applicable and appropriate and using them together provided a holistic lens for considering the research question.

According to the Palmer theory, "we teach who we are". It is based on the notion that teaching emerges from one's 'inwardness', identity and integrity. Palmer proposed that the 'tangles' of teaching have three important sources: the subject, the learners and the inwardness of the educator (Palmer, 2007). He advocated that good teaching cannot be reduced to technique; good teaching comes from the identity and integrity of the educator (Palmer, 1997). This theory has relevance for this study, where the teacher is explored as a significant resource in environmental education in the classroom. Shulman's (1987) theory, on the other hand, purports that the knowledge base of the educator frames their own learning and teaching practice. Pedagogical Content Knowledge (PCK) is the combination of content and pedagogy, and hence this theory is also relevant for this inquiry. Shulman (1987) described PCK as a form of content knowledge comprising subject matter knowledge, knowledge of the learner, knowledge of the curriculum, knowledge of the context and knowledge of the pedagogy. A combination of these two theories supported a holistic understanding of the teacher and their practice in EE in this research. 
Figure 1: Diagrammatic representation of Shulman's theory and Palmer's theory used to interpret teachers' pedagogical choices (Source: Author)

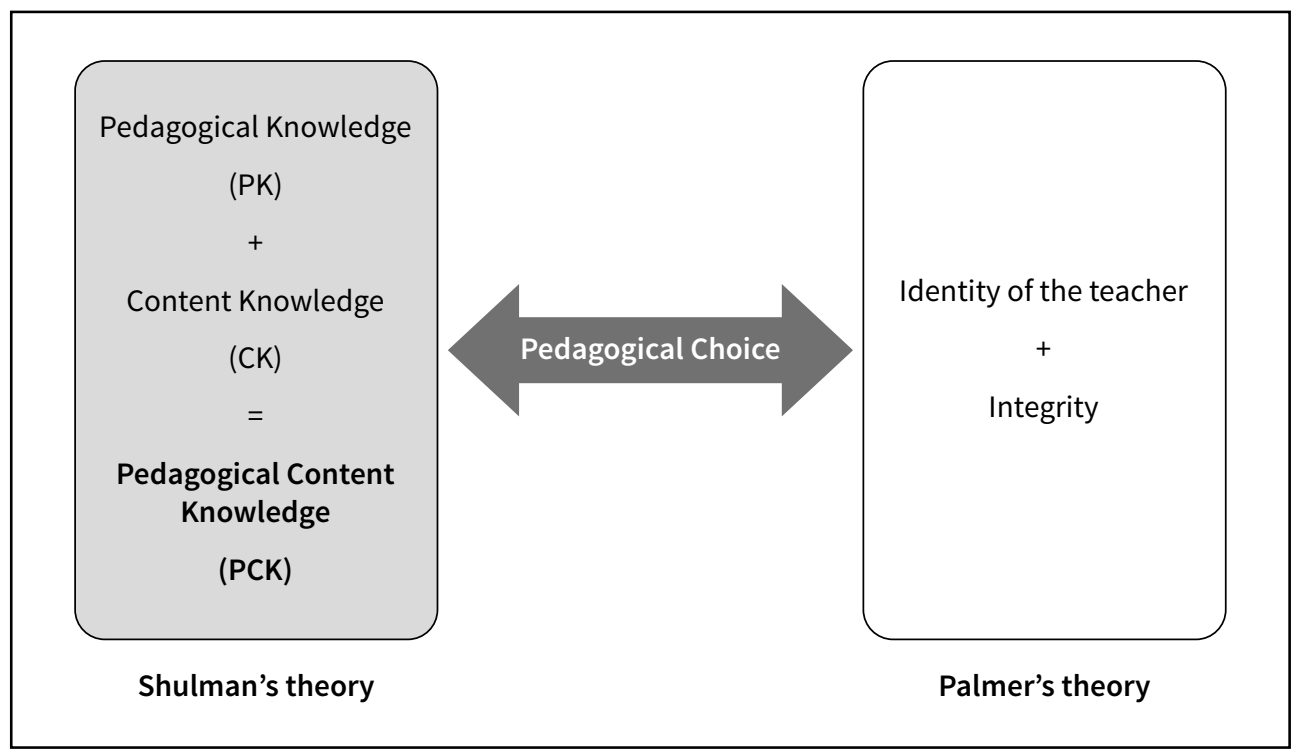

\section{Research design and methodology}

This study employed a qualitative approach in order to gain an in-depth understanding of teaching and learning in EE. Data collected from semi-structured interviews with five teachers provided insight on experiences, practice and pedagogical choices. The study was conducted at two public primary schools in KwaZulu-Natal, South Africa. The five Life Skills teachers included in the study had teaching experience ranging from 3-37 years. Teachers were coded with pseudonyms.

\section{Data collection}

The two schools were selected through purposive sampling based on proximity, similar socio-economic levels and demographic distribution. The schools are situated in residential areas with predominantly African and Indian residents in the low to middle socio-economic category with a mix of urban and rural households. Both schools have basic educational resources in place and fees are paid by parents.

\section{Piloting the interview schedule}

The initial interview questions were piloted with a Grade 5 Life Skills educator from a non-participating school. This validated the data collection instrument and allowed for screening of errors and ambiguity in the questions. After piloting, the interview schedule (see Appendix 1) was amended according to the suggestions received. 


\section{Setting up relationships}

Ethical clearance was obtained from the DUT Institutional Ethics Committee (IREC \#84/16), while gatekeeper permission was obtained from the Department of Education (SA) and the principals from each of the schools. Informed consent was provided by all participants. The principal briefed the educators about the study. Separate sessions were held with educators individually to provide details of the study and expectations regarding their role as participants.

\section{Conducting the interviews}

The purpose of the interviews was to generate information on the educator's background from inception of teaching, reasons for their career choice and most importantly, their current teaching methods and what informs their pedagogical choices. The interview schedule included questions about their rationale for choice of profession and their experiences in the field. They shared both positive experiences as well as the challenges associated with integrating EE into the primary school curriculum. The choice and use of varied teaching methods were also explored.

Demographic information was collected. The interviews were recorded on a digital audio recorder after permission was obtained from the interviewee. The interview was guided by the interviewer and interview schedule to ensure the necessary information was obtained. While all the teachers had a lack of resources in common, they had different personal experiences and attitudes towards Life Skills. In spite of this, their pedagogical choices were similar.

\section{Data analysis}

All interviews were transcribed and analysed by manual scanning for categories of responses and themes (Ngulube, 2015). Qualitative data analysis consisted of highlighting themes evident in the transcribed conversations between the educators and the researcher during interviews. The data analysis method used was a case- and theme-based approach. Themes were generated based on both the research questions, and the frequent occurrence of explanations or information provided by the participating educators. To analyse the cross-sectional descriptive data, codes and categories were developed using Shulman's framework, focusing on Pedagogical Content Knowledge as the framework. Palmer's theory was used to understand how the personal and professional aspects of teachers influence teaching. Analysis of data leads to themes which may include ordinary (predicted themes) and unexpected developing or emergent themes. Each transcript was thoroughly analysed to explore the attitudes, experiences and views of participating educators in relation to the research questions. 


\section{Results and discussion}

While teachers differed in personal experiences and attitudes, the challenge of resource limitations and subsequent teacher resourcefulness in teaching EE within the curriculum were common themes. Three overall themes emerged from the data:

(1) Challenges of embedding EE within the Life Skills curriculum and implementing EE;

(2) Resourcefulness in teaching practice; and

(3) Teacher as a resource, with and the associated need for training and professional development.

The research findings are discussed below according to these themes.

\section{The challenges of embedding and implementing environmental education within the Life Skills curriculum}

Teachers in this study perceived Life Skills as less significant than other subjects, therefore less effort or innovation was perceived to be required. Teacher $\mathrm{R}$, for example, seemed to value Maths and English more than Life Skills:

I would go more into detail with Maths and English than I do with Life Skills but not with that emphasis for Life Skills, where you say I would go out of my way to introduce it.

A similar remark was made by Teacher MO who said that he would not go the extra mile for a subject like Life Skills, whereas he would for Mathematics or Science. This could be a common perception of many teachers who teach Life Skills. It is a significant finding, because learners' interest in a subject is likely to be dampened by a teacher's negative attitude towards the subject (Jacobs, 2011).

Similar findings were reported by Ramsaroop and Van Rooyen (2013), where teachers reported challenges with interpreting the curriculum, as the written syllabus was not patently clear, and time allocation was too limited to 'get creative'. Teacher M shared that the prescribed syllabus, the Curriculum and Assessment Policy Statement (Department of Basic Education, 2011), commonly referred to by South African teachers as CAPS, was restrictive:

We are guided on teaching aspects that are specifically within the CAPS document. We can wander out, but not too much. We have to complete this within a specified time frame and we have to follow a prescribed syllabus. In certain quarters we are doing the basics.

Satchwell (2013) explained that time is often an issue in addressing EE; there is little opportunity to integrate new or innovative concepts, content or methods as the prescribed curriculum does not allow it. Creativity is also problematic when issues such as large class sizes and time constraints prevail. Teacher $S$ chose group work and simple outdoor activities for his Life Skills lessons: 
We've got such big numbers. Because we have 46, to individually assess each person takes up a lot of time. Worksheets, assessments and discussions are mostly with English. Maths, it's content knowledge. Life Skills, it's more outdoors, you teaching dancing, singing, sports, and things like that.

This reflects a notion that methods requiring little to no pedagogic effort are reserved for Life Skills, whereas 'core' subjects warrant greater attention. An intrinsic motivation and passion for the subject plays a crucial role in lesson delivery. It is essential that teachers reconsider Life Skills as equally important as the 'core' subjects. However, we need to acknowledge the challenges in South African classrooms with respect to successful EE teaching and learning.

Time-constrained teaching periods, under-resourced schools and large classes are some of the challenges reported by teachers in this study. Similar results have been found in other developing countries. Challenges include overcrowded curricula, overcrowded classrooms, an overriding focus on traditional subject examinations, high teacher workload, inadequate teaching approaches, lack of supervision and support, amongst others (Mugambi, 2013; Chirwa \& Naidoo, 2014). In this study, Teacher M, an experienced teacher with a passion for his profession, shared limitations which restricted him from incorporating various teaching methods for EE:

What hampers our progress is large class sizes. We are unable to bring them to the library to show them movies because our timetable is structured [such] that while we are teaching Life Skills, another class is in the library.

Factors such as completing the prescribed curriculum, specified time frames and the lack of appropriate physical spaces for engaging in non-traditional teaching approaches prevent the exploration and flexibility of alternate teaching methods. Large class sizes pose a challenge. The learner/teacher ratio in the two schools in this study averaged 40:1. A greater strain is placed on a teacher's time in explaining activities when introducing a new concept to a large group of students and facilitating new methods or ideas (Kimaryo, 2011). Teacher MO described these challenges:

Most of the cases we have 1:48 and our classrooms cater for 40. The desks in the classroom is one long fixed table; it creates a problem concerning group work. With Life Skills, group work is very important.

Group activities, practicals and outdoor activities linked to active learning are difficult to implement and manage in large classes. These issues were corroborated by teachers in Tanzania (Kimaryo, 2011).

Teacher $\mathrm{P}$ shared that a lack of internet access prevented her from using visual learning techniques. She felt that while some learners may enjoy reading and textbook instruction, others may find visual methods more effective in knowledge construction and understanding: 
We are always backstopped by resources. We are just as ambitious and technologically inclined to the changes but we don't have the resources.

Although teachers reported resource constraints such as the lack of textbooks and funds for field trips, there are numerous free online and print resources available. Whether these are accessed and used or not, depends on the teachers' awareness and initiative. Creative teachers are able to find appropriate online resources and and use their own innovation to overcome certain limitations.

Even though Teacher $\mathrm{P}$ was willing to incorporate technology into her teaching, she was constrained by these particular challenges in public primary schools in South Africa. The time-constrained, resource-restricted teachers explained that they can hardly complete their syllabus let alone introduce innovation into their teaching:

I have 45 learners. I can't. I wouldn't think of trying something new. Forty-five learners with

45 different emotional states, different backgrounds. I can't grasp trying something new.

(Teacher R)

Since none of the prevailing challenges are likely to be easily resolved, we have to look towards resourcefulness of the teacher in practice, as well as the use of the teachers themselves as a resource in EE. It may be possible to deliver lessons in imaginative and innovative ways despite the various resource-related challenges. This would be largely based on the PCK of the teacher to make well informed choices.

\section{Resourcefulness in teaching practice}

Although teachers are constrained by the resource-related challenges outlined above, the mere presence of teaching resources is not sufficient to guarantee that effective teaching and learning will occur. The teacher is an essential component. An imaginative, innovative and resourceful teacher is the key to a rewarding learning experience. Those teachers who were passionate about teaching were able to inspire learners despite not having many resources. Readily available resources included newspapers, the outdoors and the community. Teaching methods using these resources were not too costly or time-consuming. Although teachers listed these factors as challenges, they were able to work around them. They found innovative ways to creatively deliver lessons beyond the classroom.

Teacher $\mathrm{M}$ has supplemented his teaching with real-life examples to evoke thinking and inquiry. His use of quizzes and creative activities can be attributed to his personal professional development and his pedagogical content knowledge. Le Grange (2004) has presented a framework that includes three prominent teaching and learning approaches in EE (about, in/through and for the environment, as described by Fien, 1992). With the focus on education in/through and for the environment, knowledge becomes embedded in practice through learners' experiences with every day (real-life) social and environmental concerns. The emphasis is on changing the learners' mindsets to becoming 'thoughtful citizens' (Singh, 2011, p. 115; Swarts, Rens \& De Sousa, 2015). 
Despite challenges, the participating teachers tried to be innovative within their contexts. Teacher $\mathrm{M}$ was an advocate for using real-life situations as a platform for learning and understanding concepts (as also described by Kervinen et al., 2020). He used local newspapers, the television news and family discussions about present environmental situations to reinforce teaching:

It's very important that learners are not passive within the class, they need to be active. I create group activities for them whereby they have panel discussions or a quiz. We talk about us going to the supermarket and we buy plastic bags. I encourage learners to tell their parents not to buy these bags. As much as the CAPS document is important, [this] coupled with personal experience will give them a broader outlook in life. (Teacher $\mathrm{M}$ )

Teacher $\mathrm{M}$ supplemented his teaching with real-life examples to evoke thinking and inquiry. He did research and extensive reading to widen his view of the topic covered, so he develops his subject matter knowledge and knowledge of the context through personal inquiry. Teacher $\mathrm{M}$ encouraged learners to think and reflect on their own lives in the context of EE.

Teacher MO employed a similar technique:

We find that some children don't have tapped water, they have to walk distances to collect water so we teach them how precious water is and we teach them about the present drought.

Olatundun and Adu (2013) explained that learning occurs when it is practical and applicable in real-life settings; the personal experience of learners provides a basis for them to discuss the environment and its relationship to their daily lives. Teacher $\mathrm{M}$ and Teacher MO have developed the necessary content knowledge and pedagogic skills to incorporate such learning into their teaching. This is the definition of 'Core Competence' in relation to teacher competence as described by Clark, Triggs and Nielsen (2014).

Teacher MO used innovation in a simple form to teach EE:

I believe in taking them [learners] outside because when I do pollution we go on a walk. We use the environment and we look at things that are in the environment that causes pollution. Then we look at the sky, we look at the smoke that's coming out of the factory. Then we smell the air. We use a hands-on approach, that's how they learn Life Skills, with a hands-on approach the children really learn. Actually that's what teachers are supposed to be doing as part of teaching. They have to give worksheets and give enrichment exercises.

This cost-free exercise is an excellent way to teach EE. Teacher MO's resourcefulness enables him to teach in a captivating manner by using the senses and outdoor education.

Talking and reflecting on situations were common methods used by Teacher P. She indicated that this evokes feelings of appreciation and awareness on environmental issues among others:

Let's just reflect, what our lives would be like if we didn't have the commodity of water. And it is for the children to go back and reflect and appreciate. 
Teaching learners to reflect and appreciate is key to environmental education. Teacher P's technique of delivering the subject content and linking this with reflection on daily practice and life, is likely to be effective in teaching learners to become environmentally literate citizens. For a change in behaviour to occur, one must be able to relate learning to personal life and transform learning into action. Self-reflection was encouraged by Teacher $\mathrm{P}$ as the basis for further brainstorming, exploration and discussions of learners' experiences of any subject. She reported that her approach captures the attention of learners and intrigues them, allowing for the lesson to flow thereafter. She has noticed this effect on her learners and explained that she achieves this by ensuring her lessons are fun and interactive: "talking about something that would make them smile... think... giggle... talk and at the same time reflect it to their daily lives". Teacher S also used discussion and outdoors as a method of teaching Life Skills: "Well we have discussions, you bring up jokes and things like that. Life Skills is more about outdoors".

The learning environment created by Teacher $\mathrm{P}$ was one of freedom and she provided a platform for learning in a non-authoritarian way. She made talking, discussion and reflection fun while creating an opportunity for deep learning to occur. This process has to be facilitated by a teacher with a sufficient pedagogic knowledge base enabling use of good techniques for optimum results.

Teacher P described other techniques she used in teaching:

They had to do a survey. They educated elderly neighbours or people with little children on how to be wise in saving water. It was part of going the extra mile in taking what you learn in school and teach it to the community. We looked at the consumption of water at home to flush a toilet, have a bath, have a shower, your dishwashing and we compared both; even the garden sprinkler to the hose; and we looked at ways which water could be saved.

The home or community survey method may not be applicable for all lessons but for this one on water conservation, the cost-free use of a survey replaced an otherwise potentially monotonous chalk-and-talk exercise:

It was very beneficial because the feedback that came from the kids was WOW. Neighbours and friends commented that they didn't think there was another way of doing this. I researched this and in countries like Australia there are two drain lines where one goes for recycling water. They shared this information with their parents and other people. So the lesson that started from this research went to the class and beyond the class.

The lack of resource options disappointed passionate Teacher $\mathrm{P}$ as she has noticed the effect of different teaching methods on the response of learners:

They don't take much to audio but as soon as you put up a picture they all are interested and [the lack of resources] for me is disappointing. There are so many ways we can teach a subject besides just chalk-and-talk and write notes. 
The unavailability of resources stifled Teacher R's creativity and willingness to go the extra mile: "It's basically textbook, chalk, charts, pictures and magazines. We don't have concrete resources with the learners". Teacher $\mathrm{R}$ experienced the same challenges as the others but did not appear to make an effort to find ways to overcome these obstacles. It is thus evident that the teachers themselves are important resources in EE, and their attitude, experience and personal development regarding EE may be critical to successful teaching and learning.

\section{The teacher as a resource (identity and professional development)}

According to Palmer (1997), good teaching cannot be reduced to technique; good teaching comes from the identity and integrity of the teacher. He proposed that all the aspects of a teacher's life that have influenced them as a person, and the use of those experiences and learning, inform the professional choices of the teacher. The teacher's general understanding of the teaching of environmental education i.e. the teacher's knowledge, beliefs about the purpose and goals for teaching environmental education (what Palmer refers to as the 'why'), are important and will determine their choices with regard to instructional strategies, assessment and the use of materials and resources (Magnusson, Krajcik \& Borko, 1999). The 'who' behind the pedagogical choices, that is, the individual teacher, is important as it informs the learning, attitudes and knowledge one acquires and uses as a teacher.

Teacher $\mathrm{P}$ found her profession rewarding and her willingness to be innovative can be linked to this intrinsic factor: "It gives me an overwhelming feeling of satisfaction to know I've made a difference, a positive difference". Teacher MO shared his view on the profession and the importance of having a passion for teaching:

Teaching has got to be a passion and I have a passion for children. I'm teaching now for 34 years and if you don't have that passion for teaching you'll never get them, you got to have that love cause you know if you look at teaching, you can't become a rich man, it's got to be a passion.

Teacher M viewed his choice of career path as a result of a 'noble calling': "There were a lot of barriers nonetheless when we got into the profession and it was a noble calling, it was an outreach to the community". Researchers have also identified a teacher's commitment, knowledge of instructional methods and facilitation skills in the class as crucial in teaching Life Skills and related subjects like Life Orientation (Lamb \& Snodgrass, 2017).

Teachers in this study seemed to be confident in terms of their EE knowledge base with the exception of Teacher $\mathrm{R}$. They generally showed a positive attitude and a readiness to tackle EE teaching. Some of the teachers talked about self-learning which alluded to their own initiatives in searching for more knowledge and keeping in touch with current issues. These teachers were aware that their own learning was also lifelong and is not confined to the classroom. One teacher expressed feeling less competent in teaching EE because of a lack of formal training. Professional development is essential to boost confidence and 
improve effective delivery of EE. This is a critical issue, as teachers who are not confident and do not perceive themselves to be adequately competent in teaching EE may not be able to fulfil EE goals.

Teacher $\mathrm{M}$ enhanced and broadened his knowledge through reading, looking at subject material and observing international education and subject trends.

I'm teaching this subject for a few years now so every year I try to improve by reading, looking at new material, looking at trends that are set in other countries, not only first world countries. I look at problems that first world countries are experiencing and solutions, success stories and failures.

A teacher's self-directed inquiry and learning assists in improving pedagogical content knowledge. A simple, yet empowering tool of reading relevant literature can assist teachers with keeping abreast of their profession. The experiences, backgrounds and personalities of teachers in this research emerged as a key influence in their individual teaching methods and practices. Each teacher varied but it was clear that their individual teaching methods stemmed from their professional choices, personal experiences and intrinsic beliefs on the content or subject, demonstrating that the individual teacher is a valuable resource in EE. Teachers who viewed the profession as a calling or an opportunity to make a difference (Teacher P, Teacher M, Teacher MO and Teacher S) all demonstrated some effort in EE pedagogical choices and practices. They either incorporated outdoor education (Teacher $\mathrm{M}$ ), group work (Teacher S), surveys and community engagement (Teacher P) or discussions, case studies and news reports (Teacher MO) to supplement their teaching in an innovative way.

Teachers have been found to be reluctant in engaging learners on topics of environmental issues due to the pedagogical insecurities of their own knowledge and understanding (Satchwell, 2013). Consistent training can equip teachers with the confidence they require to initiate and conduct activities relating to environmental education. Teacher MO emphasised the need to be updated on subject matter and teaching content: "There will be new activities that we can look at to enhance the lesson".

Teachers require sufficient knowledge on environmental issues to enable them to integrate environmental aspects in their delivery of subjects apart from Life Skills. Increasing teacher experience in environmental education will enhance effectiveness of EE and cultivate environmental literacy (Yuan, et al., 2017). Investment in professional development is essential to promote an interdisciplinary approach which will enable learners to identify the environmental links with other facets of curriculum and life. The standard of education can be improved through the professional development of teachers (Pedretti \& Nazir, 2013). In the short term, teachers need to be trained to develop teaching and learning materials from the resources which are available in their environment to facilitate learning. Similar to South Africa, teachers involved in a study conducted in Tanzania did not receive training in EE when training as teachers nor had they undergone any in-service training in EE. However, some teachers felt that they were competent in 
teaching EE at primary school level, given their knowledge and self-learning which, when coupled with enthusiasm and motivation, can achieve the outcomes of EE (Burns \& Bell, 2011). Online or distance learning allows teachers the opportunity to learn in their spare time. Yuan et al. (2017) suggested newsletters as a means of regularly providing EE teachers with relevant professional knowledge and introducing EE related regulations to support teacher development.

The findings from this small-scale study suggest that teachers who are passionate about teaching and learners will find ways to use available resources as optimally as possible. It would appear that resource availability comes second to a teacher who is able to educate innovatively stemming from his/her passion for teaching. Using the theoretical frameworks, the study provided an understanding of the two facets which inform teaching method choices, namely, the pedagogical content knowledge of the teacher and the identity of the teacher. These are the professional and personal aspects of the teacher which contribute to good environmental education in the South African classroom.

\section{Conclusion}

Environmental education in the primary school classroom is an attempt at raising an environmentally literate society and teachers play a crucial role in achieving this goal. The research reported here set out to provide an insight into the actual influences on environmental education in the South African Life Skills classroom through a qualitative approach. Five Life Skills teachers participated in this study which aimed to explore the following research question: What are the factors influencing pedagogical choices for environmental education and the reasons for these choices? The findings were analysed using theoretical frameworks by Shulman and Palmer and suggest there was no evidence to support that the availability of resources or lack thereof influences pedagogical choice. Pedagogical choice seemed to be influenced by pedagogical content knowledge and teacher identity. The 'who' of the teacher surfaced as the greatest determinant of pedagogical choice.

The availability of physical and material teaching resources did not seem to be a significant determining factor for innovative teaching. The most significant factor was found to be the teacher when exploring the reasons behind good environmental education. This paper suggests that it is not the available resources that are crucial to learning, rather the presence of a resourceful teacher. The individual identity of the teacher is important when evaluating the effective delivery of EE; teachers can be both resourceful and a resource. This research study has shown that despite the challenge in availability of resources as the common thread amongst all participating teachers, most teachers were able to add a level of innovation to their pedagogical choices for EE. Those teachers that made an extra effort demonstrated positive attitudes regarding EE and the teaching profession. Teacher $\mathrm{R}$ contrasted with the other teachers in this study and clearly displayed a lack of effort stemming from her view of the teaching profession and the importance allocated to EE.

We can focus on the opportunity to aid teachers with training on the 'how' of environmental education to enable them to identify good pedagogical choices in resource- 
constrained situations. Professional development in EE is therefore essential to provide a means for introducing teachers to new strategies and materials that they may access for teaching within a resource-constrained context as is common in the South African classroom. It is also recommended that we introduce this information to potentially inform the development of pre-service teacher training programmes in focusing on the development of a resourceful environmental education teacher. Training institutions should provide the future teacher with the skills to identify innovative options for teaching. A greater emphasis should also be on the development of the teacher as a person and sustaining this development on an ongoing basis. Programmes should aim to develop resourcefulness in teachers by expanding their thinking to beyond the limits of the classroom or challenges of the school. Development of professionals should be continuous in order to ensure teachers are updated and remain relevant within their field.

\section{Notes on Contributors and their Contributions}

\section{Lead author}

Ruthanam, Melishnee

Melishnee Ruthanam is a Master's graduate in Environmental Health with a special interest in Climate Change and Environmental Education. She is a laboratory technician and works as the Integrated Learning Co-ordinator at the Durban University of Technology.

\section{Co-author}

Reddy, Poovendhree

Poovendhree Reddy is a Professor in Environmental Health in the Department of Community Health Studies at the Durban University of Technology. She is involved in environmental health education and postgraduate supervision and is a recognised scholar in this field.

\section{Co-author}

Pillay, Daisy

Daisy Pillay is a teacher educator and researcher in Teacher Development Studies. Her scholarship is in Identity Studies and focuses on teachers' personal-professional lives as the source and site for their learning and self-transformation. 


\section{Percentage contribution}

\begin{tabular}{|c|c|c|}
\hline Areas of contribution & Author & $\begin{array}{c}\text { \% Contribution per area, } \\
\text { per author } \\
(\text { each area }=100 \%)\end{array}$ \\
\hline \multirow{3}{*}{ Conception or design of the paper, theory or key argument } & Ruthanam & $40 \%$ \\
\hline & Reddy & $30 \%$ \\
\hline & Pillay & $30 \%$ \\
\hline Data collection & Ruthanam & $100 \%$ \\
\hline \multirow{3}{*}{ Analysis and interpretation } & Ruthanam & $50 \%$ \\
\hline & Reddy & $25 \%$ \\
\hline & Pillay & $25 \%$ \\
\hline \multirow{3}{*}{ Drafting the paper } & Ruthanam & $50 \%$ \\
\hline & Reddy & $30 \%$ \\
\hline & Pillay & $20 \%$ \\
\hline \multirow{3}{*}{ Critical review of paper } & Ruthanam & $40 \%$ \\
\hline & Reddy & $30 \%$ \\
\hline & Pillay & $30 \%$ \\
\hline
\end{tabular}




\section{Appendix 1: Teacher Interview Questions}

1.Tell me about your life as a teacher from the time you started? Why did you choose to study teaching?

2. What makes your teaching in the classroom enjoyable?

3. Tell me about your experience teaching Life Skills?

4. Tell me about any bad experiences?

4. Which teaching methods or styles do you prefer for EE in Life Skills?

5. Why do you prefer this/these methods?

6. Have you tried other methods?

- If not, why?

- If yes, what methods did you try?

- What were the outcomes?

7. What are your challenges regarding teaching EE using different teaching methods? 


\section{References}

Asiegbu, F.N. \& Okpala, J.U. (2019). Teacher resourcefulness as a key to improving the use of instructional materials in teaching and learning of mathematics in primary schools in Anambra state. Multidisciplinary Journal of Education, Research and Development, 3(1), 249-253.

Blyth, C. \& Meiring, R. (2018). A posthumanist approach to environmental education in South Africa: Implications for teachers, teacher development, and teacher training programs. Teacher Development, 22(1), 105-122.

Borodina, T., Sibgatullina, A. \& Gizatullina, A. (2019) Developing creative thinking in future teachers as a topical issue of higher education. Journal of Social Studies Education Research, 10(4), 226-245.

Burns, E. \& Bell, S. (2011). Narrative construction of professional teacher identity of teachers with dyslexia. Teaching and Teacher Education, 27(5), 952-960.

Cheng, I.N.Y. \& So, W.W.M. (2015). Teachers' environmental literacy and teaching - Stories of three Hong Kong primary school teachers. International Research in Geographical and Environmental Education, 24(1), 58-79.

Chirwa, G. \& Naidoo, D. (2014). Curriculum Change and Development in Malawi: A historical overview. Mediterranean Journal of Social Sciences, 5(16), 336-345.

Clark, A., Triggs, V. \& Nielsen, W. (2014). Cooperating teacher participation in teacher education: A review of the literature. Review of Educational Research, 84(2), 163-202.

Department of Basic Education. (2011). Curriculum and Assessment Policy Statement (CAPS). Geography Grade 10-12. Pretoria.

Department of Basic Education. (2018). Education Statistics in South Africa 2016. Retrieved from https://www.education.gov.za/Programmes/EMIS/ StatisticalPublications.aspx.

Fien, J. (1992). Education for the Environment: Critical curriculum theorising and environmental education. Melbourne: Deakin University Press.

Jannah, M., Halim, L., Meerah, T.S.M. \& Fairuz, M. (2013). Impact of environmental education kit on students' environmental literacy. Asian Social Science, 9(12), 1-12.

Jacobs, A. (2011). Life Orientation as experienced by learners: A qualitative study in North-West Province. South African Journal of Education, 31(2), 212-223.

Kärkkäinen, K. (2012). Bringing About Curriculum Innovations, OECD Education Working Papers, No. 82, OECD Publishing. doi: 10.1787/5k95qw8xzl8s-en.

Kervinen, A., Roth, W., Juuti, K. \& Uitto, A. (2020). The resurgence of everyday experiences in school science learning activities. Cultural Studies of Science Education, 15, 1019-1045.

Kimaryo, L. (2011). Integrating Environmental Education in Primary School Education in Tanzania: Teachers' perceptions and teaching practices. Turku, Finland: Abo Akademi University Press. 
Lamb, S. \& Snodgrass, L. (2017). A nonviolent pedagogical approach for Life Orientation teacher development: The Alternatives to Violence Project. Educational Research for Social Change, 6(2), 1-15.

Le Grange, L. (2004). Against Environmental Learning: Why we need a language of environmental education. Southern African Journal of Environmental Education, 21, 134-140.

Loubser, C., Azlin, Y.N., Dreyer, J. \& Azyyati, A.K.N. (2014). The effectiveness of environmental education workshops for teachers, learners and schools in Malaysia. Environment, Development and Sustainability, 16, 1163-1176.

Marques, R. \& Xavier, C.R. (2020). The challenges and difficulties of teachers in the insertion and practice of environmental education in the school curriculum. International Journal on Social and Education Sciences, 2(1), 49-56.

Magnusson, S., Krajcik, J. \& Borko, H. (1999). Nature, sources, and development of pedagogical content knowledge for science teaching. In J. Gess-Newsome \& N.G. Lederman (Eds.), Examining Pedagogical Content Knowledge. Boston: Kluwer Academic Publishers. pp.95-132.

Mudaly, R. \& Ismail, R. (2016). Professional development in environmental and sustainability education: Voices, practices and reflections of science teachers. Southern African Journal of Environmental Education, 32, 65-86.

Mugambi, M.M. (2013). Teachers' perceptions on how selected school factors affect learning in pre-schools in Meru South district, Tharaka Nithi County, Kenya. Unpublished master's thesis, Faculty of Education, University of Nairobi, Kenya.

Mwendwa, B. (2017). Learning for sustainable development: Integrating environmental education in the curriculum of ordinary secondary schools in Tanzania. Journal of Sustainability Education, 12. doi:10.25073/0866-773X/65.

Ngulube, P. (2015). Qualitative data analysis and interpretation: systematic search for meaning. In E.R. Mathipa \& M.T. Gumbo (Eds.), Addressing research challenges: Making headway for developing researchers. Noordwyk: Mosala-MASEDI. pp.131-156.

Olatundun, S. \& Adu, E. (2013). Impact of outdoor educational activities and gender on pupils' knowledge of environmental issues and problems in selected primary schools in Nigeria. International Journal of Economy Management and Social Sciences, 2(8), 585-592.

Palmer, P.J. (1997). The heart of a teacher identity and integrity in teaching. Change: The Magazine of Higher Learning, 29(6), 14-21.

Palmer, P.J. (2007). A new professional: The aims of education revisited. Change: The Magazine of Higher Learning, 39(6), 6-13.

Pedretti, E. \& Nazir, J. (2014). Tensions and opportunities: A baseline study of teachers' views of environmental education. International Journal of Environmental and Science Education, 9(3), 265-283. 
Ramadhan, S., Sukma, E. \& Indriyani, V. (2019). Environmental education and disaster mitigation through language learning. IOP Conference Series: Earth and Environmental Science, Vol. 314. 1st International Conference on Environmental Sciences 15-16 November 2018, West Sumatra, Indonesia.

Ramsaroop, S. \& Van Rooyen, H. (2013). Exploring educator competence in teaching environmental education in schools in Gauteng. Africa Education Review, 10(3), 595-613.

Richardson, G.M., Liang, L.L. \& Wake, D.G. (2014). Examining the durability of environmental education self-efficacy beliefs in preservice teaching. Applied Environmental Education \& Communication, 13(1), 38-47.

Reddy, C. (2017). Environmental education in teacher education: a viewpoint exploring options in South Africa. Southern African Journal of Environmental Education, 33, 117-126.

Satchwell, C. (2013). 'Carbon literacy practices': Textual footprints between school and home in children's construction of knowledge about climate change. Local Environment, 18(3), 289-304.

Shallcross, T., Loubser, C., Le Roux, C., O’Donoghue, R. \& Lupele, J. (2006) Promoting sustainable development through whole school approaches: An international, intercultural teacher education research and development project. Journal of Education for Teaching, 32(3), 283-301.

Shulman, L.S. (1987). Knowledge and Teaching: Foundations of the New Reform. Harvard Educational Review, 57(1), 1-23.

Singh, P. (2011). Developing a community of thinking: Assessment of environmental education. Environmental Education Research, 17(1), 113-123.

Spaull, N. (2013). Poverty and privilege: Primary school inequality in South Africa. International Journal of Educational Development, 33, 436-447.

Swarts, P., Rens, J. \& De Sousa, L. (2015). Working with environmental education pedagogies in life orientation to enhance social and environmental responsibility. Southern African Journal of Environmental Education, 31(1), 94-109.

United States Environmental Protection Agency. (2017). What is Environmental Education? https://www.epa.gov/education/what-environmental-education, visited 14 June 2021.

Winther, A.A., Sadler, K.C. \& Saunders, G. (2010). Approaches to environmental education. In A.M. Bodzin, K.B. Shiner \& S. Weaver (Eds.), The Inclusion of Environmental Education in Science Teacher Education. Dordrecht: Springer Netherlands. pp.31-49.

Yuan, K., Wu, T., Chen, H. \& Li, Y. (2017). A study on the teachers' professional knowledge and competence in environmental education. Eurasia Journal of Mathematics, Science and Technology Education, 13(7), 3163-3175. 